\title{
The Information Technology Model Curriculum
}

\author{
Mike Hart \\ University of Cape Town, Cape Town, South Africa \\ mhart@commerce.uct.ac.za \\ Introduction to the Special Series
}

The Information Technology Model Curriculum is the latest in a series of curricula designed to describe the body of knowledge, and recommend core and elective material suitable for undergraduate study in computing-related areas. This valuable initiative has seen much effort and broad participation by many individuals and institutions. This Special Series of the Journal of IT Education contains seven papers relating to this new IT Model Curriculum. Before outlining their contents, a brief overview will be given of computing curricula, and the IT Model Curriculum will be placed in context.

\section{Computing Curricula}

The earliest computing curriculum was published in 1968 for computer science (CS) by the Association for Computing Machinery (ACM), and in 1977 the Computer Society of the Institute for Electrical and Electronic Engineers (IEEE-CS) provided its first curriculum recommendations. The Association for Information Technology Professionals (AITP - formerly DPMA) first provided curriculum recommendations for information systems (IS) in 1985. In 1997 the Association for Information Systems (AIS), jointly with ACM and AITP, produced the IS'97 curriculum for IS. Many subsequent reports have followed the initial efforts of these societies (CC2005).

In the late 1980's the ACM and the IEEE-CS together formed a task force to create curricula for computer science and computer engineering, known as CC'91. After the major expansion of computing in the 1990's, they formed another joint task force, aimed at producing an updated volume of CC'91, Computing Curricula 2001 (CC2001). It soon became apparent that, with the "dramatic growth" and many changes in the computing area, a new approach was needed. Commenting that "...there is no question that computing in the 21 st century encompasses many vital disciplines with their own integrity and pedagogical traditions", it was decided that separate volumes should be produced for each of computer science, computer engineering, information systems and software engineering, with allowance made for future possible disciplines in the computing area. CC2001 included a revised computer science curriculum (CS2001), and subsequently separate curricula reports were issued for information systems (IS2002), software engineering (SE2004) and computer engi-

Material published as part of this journal, either on-line or in print, is copyrighted by the publisher of the Journal of Information Technology Education. Permission to make digital or paper copy of part or all of these works for personal or classroom use is granted without fee provided that the copies are not made or distributed for profit or commercial advantage AND that copies 1) bear this notice in full and 2) give the full citation on the first page. It is permissible to abstract these works so long as credit is given. To copy in all other cases or to republish or to post on a server or to redistribute to lists requires specific permission and payment of a fee. Contact Editor@JITE.org to request redistribution permission. neering (CE2004).

Two important guiding principles of the Computing Curricula 2005

(CC2005) Overview Report are:

- The dramatic growth in the number of computing disciplines and their collective impact on society requires that 
the computing disciplines articulate a shared identity.

- Each computing discipline must be a participant in defining the identities and choices as articulated in this report.

This implies that "each computing discipline must articulate its own identity, recognize the identities of the other disciplines, and contribute to the shared identity of computing", and that it is important to "offer society a practical vision of our shared field" (CC2005).

\section{Formulating an IT Curriculum}

After informal meetings between faculty whose institutions offered early IT programs, the first Conference on IT Curriculum (CITC-1) was held in 2001. Two committees were formed, one to formulate accreditation standards for IT Education, and the other to formulate a model curriculum for IT. The Society for Information Technology Education (SITE) was also launched. In 2003, SITE became an ACM Special Interest Group (SIGITE), and a curriculum committee started work on a draft curriculum document, following the format of CS2001. Recognizing the new IT discipline, the CC2005 document incorporated it in the revised structure of Figure 1 as IT2006.

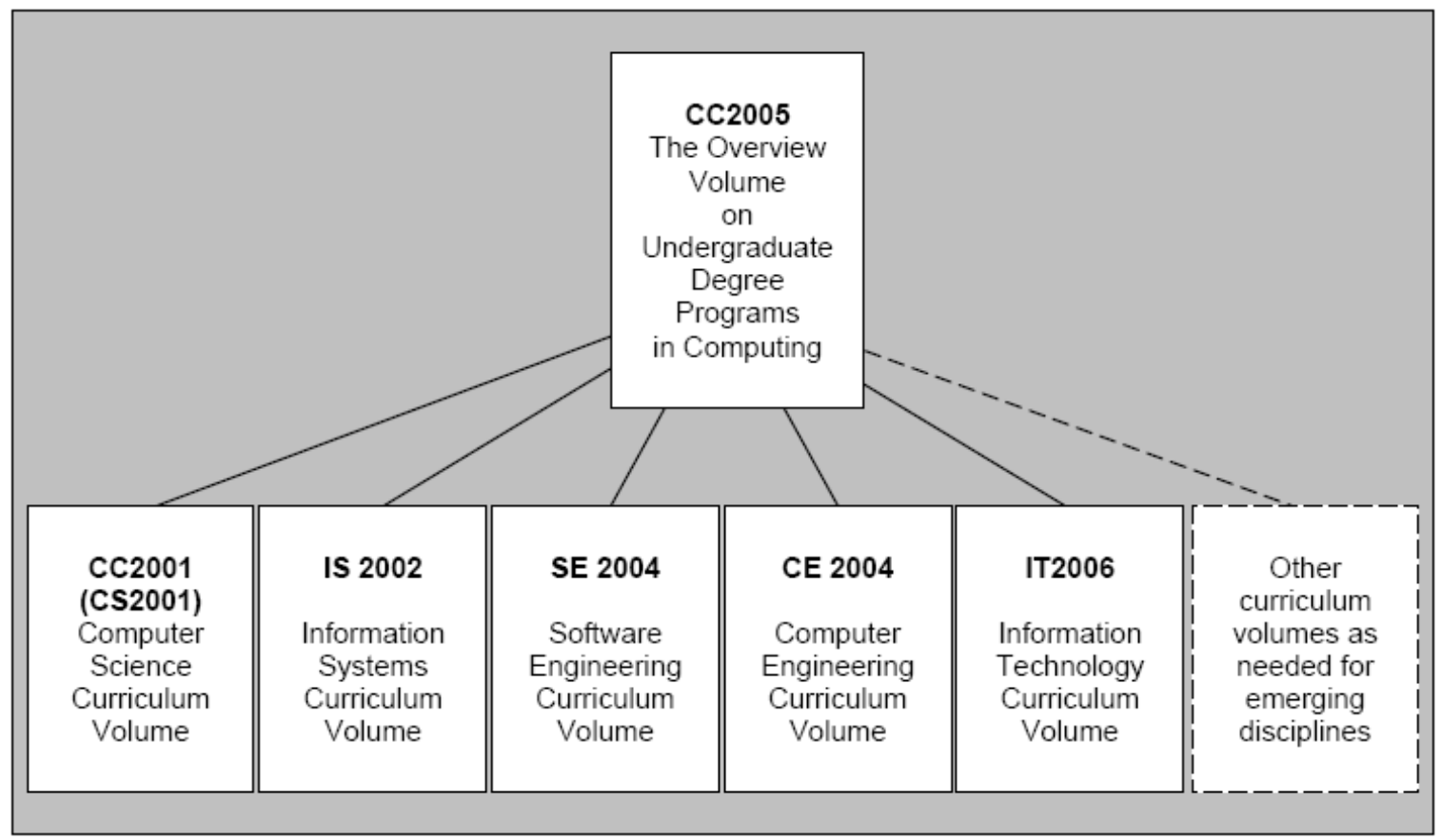

Figure 1: Structure of the Computing Curricula Series (Source: CC2005)

Since 2003, the SIGITE Curriculum Committee and its Writing Subcommittee have published a series of drafts of the IT Model Curriculum and made them available for public comment on the SIGITE website (http://www.acm.org/education/curric vols/IT October 2005.pdf). Many conference presentations have also been given by committee members and others, and material was published in 2004 in the Journal of IT Education (JITE). In order to give readers a brief highlevel overview of the content and focus of the IT model curriculum, some of the most important summary features of the most recent (October 2005) draft are now listed:

The body of knowledge for an IT baccalaureate program contains the following knowledge areas (IT2005): 
- Information Technology Fundamentals (ITF)

- Human Computer Interaction (HCI)

- Information Assurance and Security (IAS)

- Information Management (IM)

- Integrative Programming \& Technologies (IPT)

- Networking (NET)

- Programming Fundamentals (PF)

- Platform Technologies (PT)

- Systems Administration and Maintenance (SA)

- System Integration \& Architecture (SIA)

- Social and Professional Issues (SP)

Each knowledge area is broken down into a number of units, to which a suggested number of core hours of class time is attached. Each unit covers a range of topics, and has associated core learning outcomes and elective learning outcomes.

In addition, the curriculum committee suggested that certain aspects should be "woven like threads through the tapestry of the IT curriculum" (IT2005). These so-called "pervasive themes" are:

- User centeredness and advocacy

- Information assurance and security

- The ability to manage complexity through: abstraction and modeling, best practices, patterns, standards, and the use of appropriate tools

- A deep understanding of information and communication technologies and their associated tools

- Adaptability

- Professionalism (life-long learning, professional development, ethics, responsibility)

- Interpersonal skills

The above brief summary is given purely to outline the focus of the IT model curriculum content. Readers should see the full 115 page draft document to gain more detail, and to appreciate the philosophy, principles and other aspects of this model curriculum.

\section{Papers in this Special Series}

The first paper in this Special Series is appropriately authored by the seven members of the writing subcommittee of the IT curriculum committee: Joseph Ekstrom, Sandra Gorka, Reza Kamali, Eydie Lawson, Barry Lunt, Jacob Miller and Han Reichgelt. Their article "The Information Technology Model Curriculum" provides valuable insights into the development of this curriculum. The paper takes us back to 2001, when the first Conference for IT Curriculum (CITC-1) was held, SITE was formed, and a Delphi study conducted to assess the topics that should be included in an IT program. It describes key principles adopted by the curriculum committee, and discusses the influence on the curriculum of the accreditation criteria for programs in computing and information technology, as well as that of the Computing Curricula Project. The paper explains the process followed and the rationale behind key decisions taken in formulating the model curriculum. This includes the development of knowledge areas, knowledge units, and topics, with associated core and elective learning outcomes, as well as the concept of pervasive themes. In "A Curriculum Model Based on the SIGITE Guidelines", Reza Kamali, Samuel Liles, Charles Winer, Keyuan Jiang and Barbara Nicolai describe the outcomes-based process of curriculum 
revision they followed in implementing the IT model curriculum in their university department. Drawing on advice of industry experts, hiring agencies and advisory committee members, goal statements for "primary track" degree specializations were developed. These were crossreferenced with learning outcomes from the IT2005 model curriculum knowledge areas. The article describes how appropriate knowledge areas were incorporated into the revised departmental curriculum structure, which also incorporates a complementary secondary track. The authors comment on a number of benefits gained by using the outcomes-based approach.

Cheryl Aasheim, Choong Kwon Lee and Han Reichgelt focus on the IT Fundamentals (ITF) knowledge area in their article "An Implementation of the IT Fundamentals Knowledge Area in an Introductory IT Course". The ITF knowledge area aims to give students a broad understanding of the IT profession and its required skills, as well as the academic discipline of IT and its relationship to other disciplines. These aspects would best be covered in an introductory IT course. Such courses typically also include time spent on gaining skills using office or productivity tools, and may also need to incorporate certain other topics as building blocks for follow-on courses. It may therefore be difficult to encompass all of these fully in the normal time parameters of a course. The article demonstrates how the authors have been able to deal with this difficulty in their implementation. They also illustrate the extent to which the different knowledge units of the ITF knowledge area can be covered by existing textbook material, and where supplementary material may be required. Finally they show how ITF learning outcomes may be assessed in various ways.

One of the pervasive themes identified during the development of the curriculum is Information Assurance and Security. Melissa Dark, Joseph Ekstrom and Barry Lunt cover this aspect in their paper "Integrating Information Assurance and Security into IT Education: A Look at the Model Curriculum and Emerging Practice". IAS is the only pervasive theme that is also defined as a separate knowledge area. The authors discuss the way in which courses and certification in information assurance education have developed at universities in the USA. They describe a model for IAS that can be used to form the basis for applying it as a pervasive theme in education. In addition they describe the integration of IAS into curricula at two universities, and suggest a number of general approaches for incorporating IAS as a pervasive theme in IT curricula.

Elayne Shields-Bryant looks more broadly at "Academic Standards for Developing, Implementing, Evaluating, and Improving Information Science and Technology Baccalaureate Degrees". She examines the accreditation criteria of programs accredited by the Computing Accreditation Commission (CAC), the American Library Association (ALA), Technology Accreditation Commission (TAC), and the Association to Advance Collegiate Schools of Business (AACSB), finding categories common to many of these. After preliminary testing, a list of 138 criteria covering 15 categories are developed and sent to individuals affiliated to the Accreditation Board for Engineering and Technology (ABET), the American Library Association (ALA), American Society for Information Science and Technology (ASIS\&T), the Business Accreditation Committee (BAC) and the Computer Sciences Accreditation Board (CSAB). Respondents show general agreement with all categories, and give useful pointers to the split of semester hours by topic, and to levels of faculty involvement.

Jonathan Ezer draws international IT curricular comparisons in his paper "India and the USA: A Comparison Through the Lens of Model IT Curricula". He examines the model curriculum for IT published by the All India Council for Technical Education (AICTE), contrasting its 21 main knowledge topics, and the time allocated to each, with the 12 knowledge areas of the USA-based IT2005 model curriculum. Ezer finds that eight of these areas are similar, but that there are major differences between the other knowledge areas specified in the two model curricula. The Indian curriculum places a strong emphasis on core science and engineering courses, as well as business and marketing, with guiding principles linked to the country's economic progress. The other four 
USA curriculum areas are IT-related, but there is also an understanding that students should familiarize themselves with various application domains, without specifying any associated time allocations. This illustrates a difference of approach between these two curricula, and indicates how understanding of the requirements for developing IT skills may vary.

Jeffrey Brewer, Alka Harriger and John Mendonca describe an application of the model curriculum in their article "Beyond the Model: Building an Effective and Dynamic IT Curriculum". Their paper proposes a continuous improvement process framework for developing a comprehensive and adaptive IT curriculum, consisting of the phases: collect, evaluate, design and implement. The authors stress the importance of adapting the IT model curriculum to an institution's mission and goals, and taking into account local and regional needs, availability of expertise and technical resources. Requirements need to be collected from a wide range of stakeholders, and then carefully evaluated in terms of an overall strategic plan. For creation of an effective curriculum, design and implementation is of necessity iterative and incremental in the dynamic IT environment, and continuous assessment is also important. The authors describe how a department's situation may affect the approach taken, and give useful guidelines for following this process.

\section{Conclusions}

The Information Technology Model Curriculum has been carefully developed and publicised by the SIGITE curriculum committee and writing subcommittee over a period of five years, taking into account the views and feedback of a large number of participants and stakeholders. IT has been recognized by the Joint Task Force for Computing Curricula (CC2005) as a new discipline in the computing arena, with its own programs and its own evolving model curriculum, labelled in CC2005 as IT2006. The process followed in getting to the present stage of IT2005 was well documented in the first paper of this Special Series.

Other articles in this Special Series confirm that this model curriculum is not a rigid specification and end in itself, but a solid and meaningful base which may be adapted where necessary to suit the varied environments of different institutions. Examples have been given of how this has been carried out, with particular attention being paid to possible processes for implementation and ongoing enhancement and assessment in a dynamic environment. Two papers have focussed in more detail on specific knowledge areas and pervasive themes, giving useful ideas on how to incorporate these fully in undergraduate programs. A broader canvas has also been used to compare key elements of the IT model curriculum with that of another country, and to gauge acceptance of a wide range of academic standards across a set of IST-related accrediting bodies.

The IT Model Curriculum, together with the CC2005 Overview Report, enables readers from within and outside the IT and computing environments to gain a clear understanding of the focus of undergraduate IT programs in the broad computing landscape. It will greatly assist those charged with developing programs of this nature, and enable those teaching IT subjects to gain a solid and holistic perspective of this new discipline. As the IT landscape is dynamic, modifications will need to be made to curricula and programs on a regular basis, and these can hopefully be well informed by those who pioneer the use of the Information Technology Model Curriculum.

\section{References}

[CC2001] ACM/IEEE-Curriculum 2001 Task Force. (2001). Computing Curricula 2001, Computer Science. IEEE Computer Society Press and ACM Press, December 2001. (http://www.computer.org/curriculum or http://www.acm.org/education/curricula.html) 
[CC2005] Joint Task Force for Computing Curricula. (2005). Computing curricula 2005: The overview report. ACM, AIS and IEEE-CS, 30 September 2005. (http://www.acm.org/education/curric vols/CC2005-March06Final.pdf)

[CE2004] IEEE/ACM Joint Task Force on Computing Curricula. (2004). Computer Engineering 2004. Curriculum Guidelines for Undergraduate Degree Programs in Computer Engineering. IEEE Computer Society Press and ACM Press, December 2004. (http://www.computer.org/curriculum or http://www.acm.org/education/curricula.html)

[IS2002] ACM/AIS/AITP Joint Task Force on Information Systems Curricula. (2002). IS2002 Model Curriculum and Guidelines for Undergraduate Degree Programs in Information Systems, Association for Computing Machinery, Association for Information Systems, and Association for Information Technology Professionals. (http://www.acm.org/education/curricula.html or http://www.computer.org/curriculum)

[IT2005] The ACM SIGITE Task Force on IT Curriculum. (2005). Information Technology 2005, Curriculum Guidelines for Undergraduate Degree Programs in Information Technology, IEEE Computer Society Press and ACM Press, October 2005. (http://www.acm.org/education/curric_vols/IT_October_2005.pdf).

[SE2004] IEEE/ACM Joint Task Force on Computing Curricula. (2004). Software Engineering 2004, Curriculum Guidelines for Undergraduate Degree Programs in Software Engineering, IEEE Computer Society Press and ACM Press, August 2004. (http://www.computer.org/curriculum or http://www.acm.org/education/curricula.html)

\section{Acknowledgements}

I would like to thank the authors of these seven papers for their valuable contributions to this special series. Thanks also go to all reviewers for their time and helpful comments.

\section{Biography}

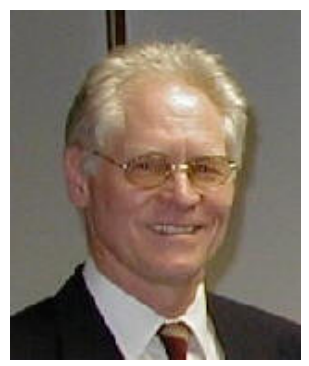

Currently Professor in the Department of Information Systems at the University of Cape Town, South Africa, Mike teaches mainly postgraduates and supervises research, and was previously H.O.D. He has an MSc (Distinction) in Operations Research and a PhD in Mathematical Statistics from UCT, and did post-doctoral studies at the London School of Economics and Stanford University. He has held planning, distribution and I.S. management positions in retailing, financial services and manufacturing. With many accredited local and international publications, his research and consulting interests are mainly in business intelligence and analytics in organizations. He is pres-

ently on the editorial boards of JITE, JITCAR and EJBRM. 